\title{
Thyroid Cell Irradiation by Radioiodines: A New Monte Carlo Electron Track-Structure Code
}

\author{
Christophe Champion $^{1 *}$, Mouhamad Elbast ${ }^{2}$, Ting-Di Wu $\mathbf{u}^{3}$ and Nicole Colas-Linhart ${ }^{2}$ \\ ${ }^{1}$ Laboratoire de Physique Moléculaire et des Collisions; Université Paul Verlaine-Metz; boulevard Arago; \\ Technopôle 2000; champion@univ-metz.fr; 57078 Metz - France. ${ }^{2}$ Laboratoire de Biophysique; Faculté de \\ Médecine; Université Paris 7; Denis Diderot; BP 416; 75870 Paris cedex 18. ${ }^{3}$ INSERM U759; Imagerie \\ Intégrative; Institut Curie Recherche; Bât. 112; Centre Universitaire; 91405 Orsay
}

\begin{abstract}
The most significant impact of the Chernobyl accident is the increased incidence of thyroid cancer among children who were exposed to short-lived radioiodines and 131-iodine. In order to accurately estimate the radiation dose provided by these radioiodines, it is necessary to know where iodine is incorporated. To do that, the distribution at the cellular level of newly organified iodine in the immature rat thyroid was performed using secondary ion mass microscopy $\left(N a n o S I M S^{50}\right)$. Actual dosimetric models take only into account the averaged energy and range of beta particles of the radio-elements and may, therefore, imperfectly describe the real distribution of dose deposit at the microscopic level around the point sources. Our approach is radically different since based on a track-structure Monte Carlo code allowing following-up of electrons down to low energies $(\approx 10 \mathrm{eV})$ what permits a nanometric description of the irradiation physics. The numerical simulations were then performed by modelling the complete disintegrations of the short-lived iodine isotopes as well as of ${ }^{131}$ I in new born rat thyroids in order to take into account accurate histological and biological data for the thyroid gland.
\end{abstract}

Key words: Thyroid; iodine radioisotopes; Monte Carlo simulation; cellular dosimetry

\section{INTRODUCTION}

The most significant consequence of the Chernobyl accident is the increased incidence of thyroid cancers in children and adolescents who were exposed to radioiodines in fallouts resulting from atmospheric release (Shibata et al., 2001; Heidenreich et al., 2001). Since then, there has been renewed interest in radioiodine thyroid dosimetry and in the effects of radioiodines, especially in children (Zanzonico, 2000; Heidenreich et al., 2001).

Thyroid cancers were then mainly attributed to 131-iodine $\left({ }^{131} \mathrm{I}\right)$ (Jacob et al., 1999, Cardis et al.,
2005) with only a few studies (Bleuer et al., 1997, Balonov et al., 2003) pointing out the role of shortlived radioiodines in the increased incidence of thyroid cancers. Indeed, the unusually short latency between exposure and clinical manifestations of thyroid cancer could be more consistent with the expected effects of highenergy, short-lived radioiodines. Moreover, radioiodine dosimetry to the thyroid, either after therapeutic use or accidental exposure, is always based on the hypothesis of a uniformly distributed activity within the gland resulting in a uniform irradiation of the organ (Loevinger et al., 1968; Goulko et al., 1996). In addition, conventional

* Author for correspondence 
methods for radiation dose calculations implicitly assume that the radiation dose received by each cell is the same as the dose the entire organ received. However, as early as 1956, Sinclair et al., (1956) showed the heterogeneity of ${ }^{131} \mathrm{I}$ incorporation within the thyroid using autoradiography. Precise knowledge of the cellular distribution of iodine is an essential prerequisite to develop a dosimetric model. Indeed, dosimetric studies must be performed at the cellular level. To do that, we have coupled a geometrical thyroid model, obtained after secondary ion mass spectrometry (SIMS) studies, and to a complete electron Monte Carlo (MC) transport code in biological matter recently developed (Champion, 2003). Indeed, charged particle track-structure analysis is a useful basis for the understanding of early physical and chemical stages of radiation actions on matter in general. This holds true especially in radiation biology, i.e., in research on the effects of radiation on the biological cell, which has a highly inhomogeneous spatial and chemical structure. However, let us note that trackstructure analysis based on computer simulations requires as input data cross sections in order to describe, step-by-step, all the interactions induced by charged particles with molecules in matter under consideration like water which is the dominant component of the biological cell of soft tissues. Moreover, contrary to the major part of the existing codes which essentially use semiempirical fits of experimental singly differential and total cross sections (Uehara et al., 1992; Uehara 1986), the present MC code is based on a complete set of theoretical cross sections of the most important electronic processes involved in the full slowing-down histories in water for electrons of several $\mathrm{MeV}$ down to a few electron volts.

The purpose of the present study is to describe the kinetic follicular distribution of newly organified iodine in rat immature thyroids. In the following, we briefly present the characteristics of the NanoSIMS ${ }^{50}$ techniques as well as the great lines of the theoretical Monte Carlo code we have developed for the electron following-up simulation. Finally, a detailed study of the fine structure of the radioiodine decays in the thyroid is presented in order to provide an accurate cellular microdosimetry.

\section{MATERIAL AND METHODS}

\section{Geometrical Thyroid Model for Kinetics of the Radioiodine Isotope Distribution}

\section{Animal model}

The study was carried out on Wistar newborn rats fed by suckling from their mother. To mimic a contamination by radioiodine, all pups ( 7 days old) received one subcutaneous injection of $0.2 \mu \mathrm{g}{ }^{129} \mathrm{I}$ $\left({ }^{129} \mathrm{I}^{-\mathrm{Na}^{+}}\right.$, NEN Life Science products, Boston MA, USA), with an activity of $1.2 \mathrm{~Bq}$, in a $50 \mu \mathrm{l}$ volume. Pups were sacrificed by exsanguination 1 hour to 8 days after ${ }^{129} \mathrm{I}^{-\mathrm{Na}^{+}}$administration. Thyroids of control and "contaminated" pups were removed, fixed, washed, dehydrated in alcohol series, and embedded in epoxy resin. Serial thin sections (thickness $0.5 \mu \mathrm{m}$, surface about $1 \mathrm{~mm}^{2}$ ) were deposited on stainless steel disks for SIMS analysis.

\section{SIMS Analysis}

Isotopic analysis was used to discriminate between the natural isotope 127 -iodine $\left({ }^{127} \mathrm{I}\right)$, the isotope of the initial pool of iodine and ${ }^{129} \mathrm{I}$, the isotope of the newly incorporated iodine. SIMS observations were carried out on a NanoSims $50^{\mathrm{TM}}$ whose main characteristics are: $i)$ a high lateral resolution, ii) the ability to measure in parallel up to 5 masses (ions) in the same micro volume, iii) a very good mass transmission at high resolutions, and finally, iv) a direct and optical observation of the sample in the ionization chamber allowing easy selection of areas of interest (Guerquin-Kern et al., 2005). Separate images were recorded for the initial iodine pool $\left({ }^{127} \mathrm{I}\right)$ and the distribution of newly organified iodine $\left({ }^{129} \mathrm{I}\right)$. Topography was revealed using ${ }^{31} \mathrm{P}$, which associates with DNA in the cellular nucleus, and ${ }^{32} \mathrm{~S}$, which allows the identification of the colloid.

The main advantage of SIMS microscopy is the ability to make direct observations of the distribution of any element occurring at the surface of a sample, with no need for specific labelling with a fluorescent or radioactive probe. Nevertheless, the main difficulty with SIMS microscopy is the signal specificity, which is highly dependent on mass resolution: the complexity of the organic matrix leads to the emission of a large number of ions, which can interfere with the study element. The latest highresolution dynamic SIMS device that we used in our work has both a very good transmission at 
high mass resolutions, and a high lateral resolution $(\leq 50 \mathrm{~nm})$. Recently, the ultra-structural localization of ${ }^{127}$ I-benzamide uptake in melanin grains within melanocytes was performed using the NanoSims $50^{\mathrm{TM}}$ device (Guerquin-Kern et al., 2004).

\section{Geometrical Thyroid Model}

From newborn rat thyroid image (Fig. 1a), morphometrical studies were performed and we have modelled the thyroid follicle by two concentric spheres (see Figure 1b): a first one of $12 \mu \mathrm{m}$ diameter to represent the colloid itself and a second one of $(12+8) \mu \mathrm{m}$ diameter to represent the cellular shell, what leads to a mean number of 32,84 cells per follicle, each of them having a volume of $800 \mu \mathrm{m}^{3}$.

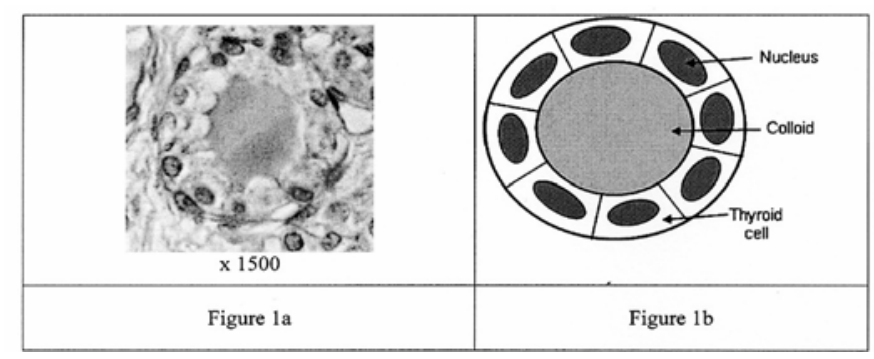

Figure 1 - Image (a) and diagram (b) of a newborn rat follicle. The follicle is the functional unit of thyroid. Iodine is extracted from the blood and then stored in organified form within the colloid

\section{Monte Carlo Simulation of Radioiodine Isotope Decays in Biological Matter}

Charged particle track-structure analysis is a useful basis for the understanding of radiation effects on living matter, which has a highly inhomogeneous spatial and chemical structure. To do that, the preferential method is the Monte Carlo simulation, which consists in describing, step-bystep, interaction after interaction, the history of each ionizing particle created during the irradiation of the biological matter. In this kind of numerical code, each projectile-target interaction is described thanks to multi-differential and total cross sections giving access to a complete description of the kinematics before and after the collision. The Monte Carlo track-structure code we have recently developed allows a complete description of $\gamma$ disintegration and provides a detailed energetic cartography at the nanometric scale. To do that, we started from the decay spectrum of the radioiodine isotopes of interest and simulated a large number of disintegrations (of the order of 500000) by assuming that the biological medium was correctly modelled by liquid water. The simulation is only briefly reported in the following and for more details we refer the reader to our recent publication (Champion, 2003; Champion, 2005; Champion and Le Loirec 2006).

Table 1 - Energy spectra included into our Monte Carlo simulation. $\beta$ spectrum as well as Auger and Conversion electrons are taken into account.

\begin{tabular}{cccccc} 
Isotopes & ${ }^{\mathbf{1 3 1}} \mathbf{I}$ & ${ }^{\mathbf{1 3 2}} \mathbf{I}$ & ${ }^{\mathbf{1 3 3}} \mathbf{I}$ & ${ }^{\mathbf{1 3 4}} \mathbf{I}$ & ${ }^{\mathbf{1 3 5}} \mathbf{I}$ \\
\hline$\overline{E_{\beta}}(\mathrm{keV})$ & 182.5 & 464.1 & 390.6 & 580.9 & 341.7 \\
$\frac{E_{\text {Auger }}}{(\mathrm{EV})}(\mathrm{eV})$ & 438.6 & 69.3 & 39.5 & 180.2 & 30.1 \\
$\begin{array}{c}E_{\text {Conversion }}(\mathrm{keV}) \\
\text { Auger }+ \text { Conversion }\end{array}$ & 9.6 & 7.5 & 3.8 & 8.8 & 2.4 \\
total & $19.85 \%$ & $2.5 \%$ & $1.46 \%$ & $6.07 \%$ & $1.11 \%$ \\
\hline
\end{tabular}




\section{Description of the Biological medium}

Since water is the major component of the human body ( $80 \%$ in mass), the biological medium has been simulated by liquid water, this latter being described by means of molecular quantum wave functions expanded in terms of Slater functions centred on the oxygen nucleus. Each of the five molecular orbitals, denoted by ${ }^{1} \mathrm{~B}_{1},{ }^{3} \mathrm{~A}_{1},{ }^{1} \mathrm{~B}_{2},{ }^{2} \mathrm{~A}_{1}$ and $1 \mathrm{~A} 1$, are then expressed as a linear combination of atomic orbitals with its corresponding ionizing potential $I P_{1}=12.63 \mathrm{eV}$, $I P_{2}=14.73 \mathrm{eV}, I P_{3}=18.55 \mathrm{eV}, I P_{4}=32.20 \mathrm{eV}$ and $I P_{5}=532.0 \mathrm{eV}$, respectively (for more details see Moccia (1964)).

\section{Monte Carlo Simulation Principles}

At the beginning, the incident energy $E_{i n c}$ is selected form the energy spectrum (see above) and the electron is randomly emitted from a given point (whose coordinates are also randomly chosen) and then followed, as well as all the secondary particles created, until its energy reaches a predefined energy cut-off equal, in this work, to the $1^{\text {st }}$ Ionization Potential of the water molecule i.e. $E_{\text {cut-off }}=12.6 \mathrm{eV}$. In brief, the code determines, in a first step, the free path $\lambda$ travelled by the incident particle (i.e. the distance between two successive collisions). This procedure is made by means of direct random sampling according to the sum of all the total interaction cross sections relative to all the processes included in the simulation, namely the elastic scattering, the ionization process and the excitation process (electronic as well as rotational and vibrational). The particle is then transported to its new position and the type of collision is randomly determined by applying again direct Monte Carlo samplings according to the relative magnitude of the individual total interaction cross sections. At this stage, the collision is entirely described with the energy transfer $\Delta \mathrm{E}$ occurred during the selected interaction, the scattering direction $\left(\theta_{\mathrm{s}}, \varphi_{\mathrm{s}}\right)$ followed by either the scattered electron or the secondary electron and the ejection direction $\left(\theta_{\mathrm{e}}\right.$, $\left.\varphi_{\mathrm{e}}\right)$ followed by the ejected electron when ionization is selected. This procedure is performed applying Monte Carlo samplings in according to the multi-differential cross sections corresponding to the interaction in question. We speak of double differential cross sections when excitation and elastic scattering are selected whereas we need triple differential cross sections when ionization is chosen. All the coordinates of inelastic collisions are then stored as well as the kinematics and energetic parameters of the secondary particles, which will be used, in later iterations that treat each of these new secondary electrons as the primary particle. The new electron energy is then evaluated $\left(E_{\text {inc }}-\Delta E\right)$ and used for simulating the following sequence (see Fig. 2).

\section{Electron Collisions}

The performance of a Monte Carlo code dedicated to the following-up of electrons in matter is essentially dependent of the accuracy of the cross sections used. Under these conditions, we have recently developed a full-differential trackstructure code for electron following-up in water whose all interaction cross sections (elastic and inelastic) were theoretically calculated and successfully compared to a large set of experimental data (Champion, 2003; MilneBrownlie et al., 2004; Champion et al., 2002, $2004,2006)$. We only report in the following, the corresponding total cross sections and more details concerning the different theoretical models used for calculations can be found in our previous works. 


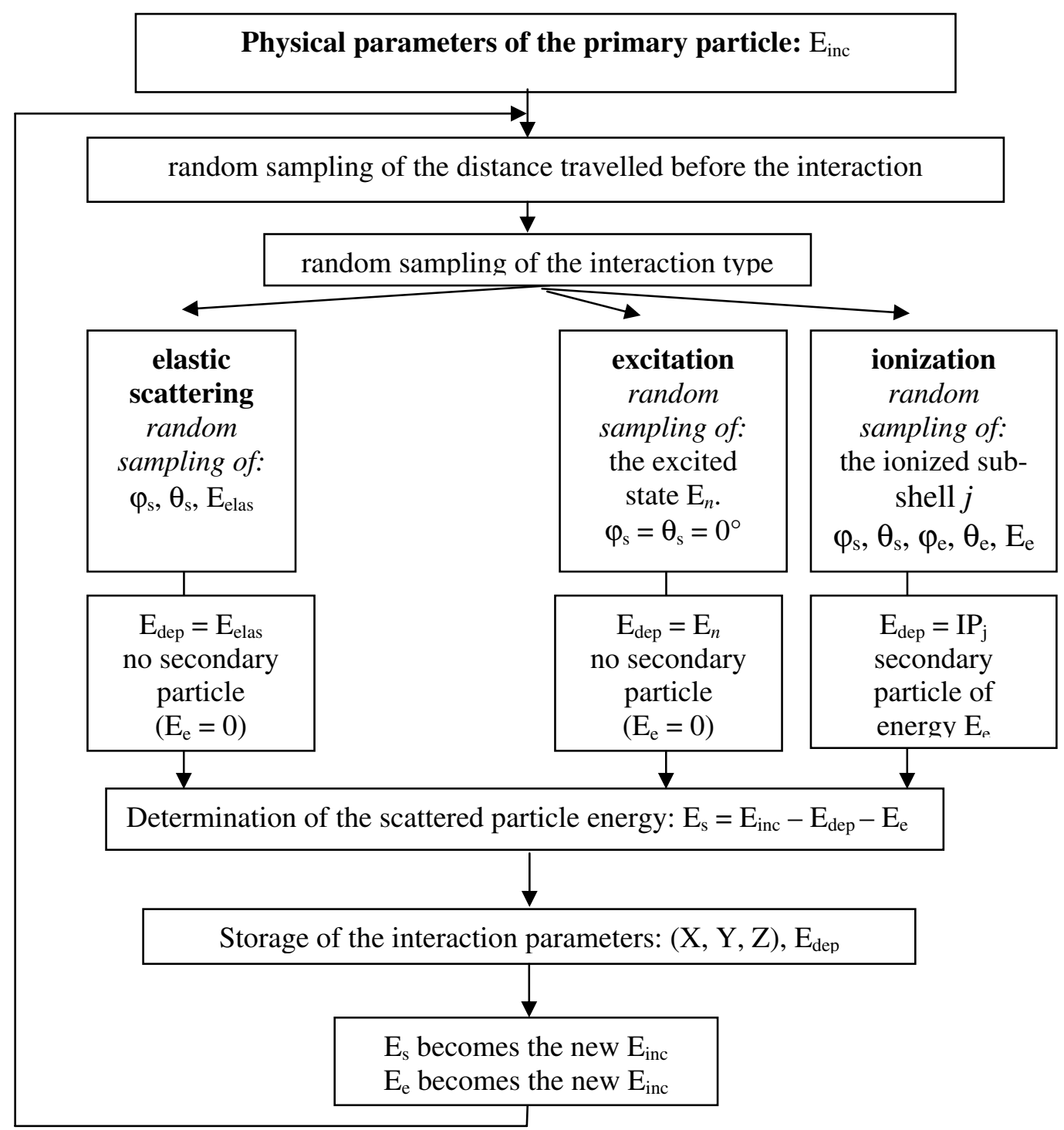

Figure 2 - Flow chart for primary and secondary electron transport

\section{RESULTS AND DISCUSSION}

Kinetics of Iodine in Rat Thyroid: the NanoSIMS Contribution

In our study, the animal model was set up to mimic the conditions of contamination at Chernobyl by radioiodine. The age of administration of ${ }^{129} \mathrm{I}$ was chosen to correspond to the contamination age where increase of thyroid cancer was greatest after the accident. In Figure 4 pseudo-colours were used to superimpose ionic images obtained for ions ${ }^{31} \mathrm{P}^{-}$ and ${ }^{129} \mathrm{I}$ at different times after administration of ${ }^{129} \mathrm{I}$. Our results clearly demonstrate that inter and intra-follicular distribution of newly organified iodine is homogeneous in newborn rat thyroid for times greater than 24 hours after administration. Under these conditions, we have decided to study, in the present work, the behaviour of the different radioiodines by considering, at first, a homogeneous distribution of the isotopes inside the colloidal matter. In further steps, more "exotic" and realistic distributions will be studied and 
proportionality of each model will be integrated in a kinetic analysis.

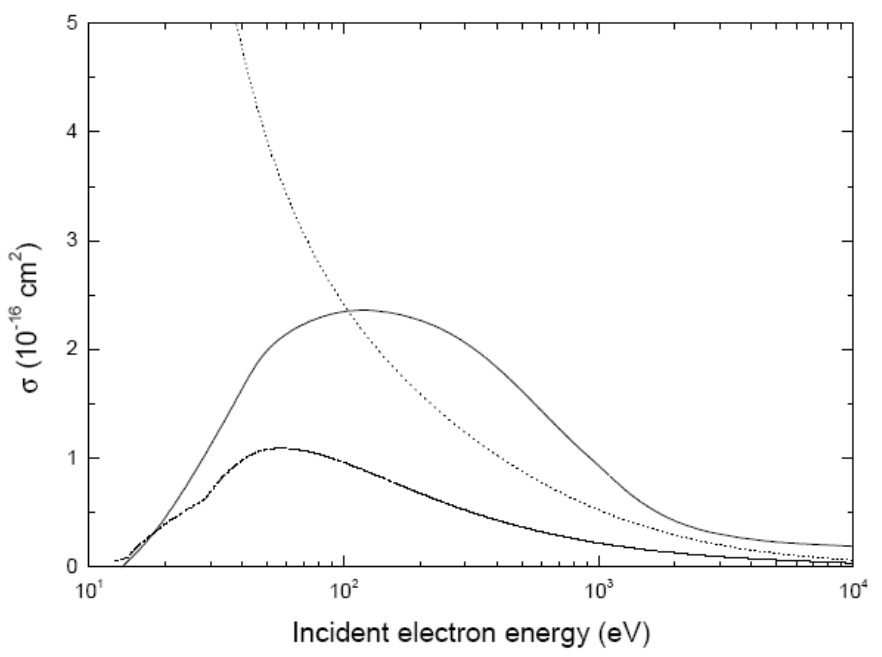

Figure 3 - Total cross sections of the electron process included in the Monte Carlo track-structure code: elastic scattering (dotted line), ionization (solid line) and excitation (dashed line)

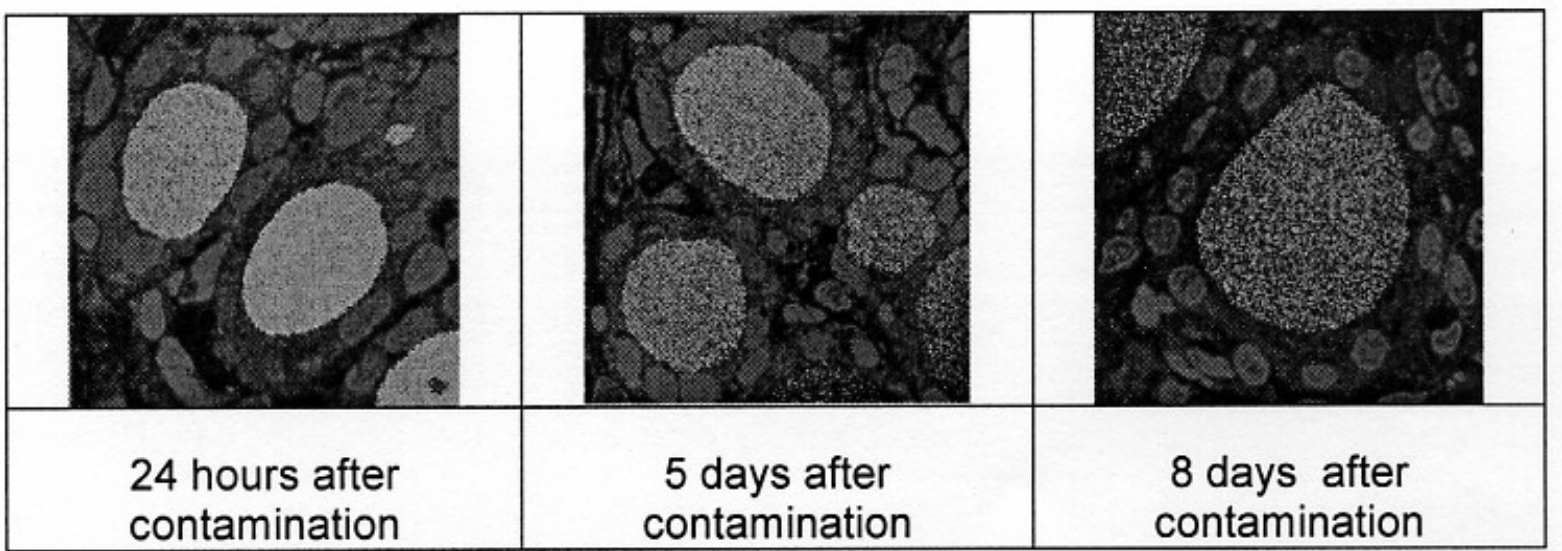

Figure 4 - Digitized images in pseudo colours with superimposition of phosphorus (green) and 129-iodine (red) for a thyroid follicle from 7 days-old rat. The images have been obtained from 24 hours to 8 days after administration of 129-iodine

\section{Monte Carlo results}

S-values in Spherical Targets Similar to Thyroid Follicles (Diameter of $24 \mu \mathrm{m}$ )

Firstly, it seemed us interesting to test our model by evaluating for each isotope: $i$ ) the mean energy emitted per disintegration and ii) the S-values i.e. the mean dose deposited per disintegration (in Gy/Bq.s) within the colloid of $24 \mu \mathrm{m}$ diameter. For each simulation a large number of disintegrations have been modelled in order to be sure that convergence was reached.

\section{Energy pattern observed during radioiodine isotope disintegrations}

Considering now the analysis of each radioisotope, we have first modelled the disintegration of 1Gy within the colloid, what corresponds to a mean 
energy of about $4,5.10^{7} \mathrm{eV}$ liberated from point sources randomly selected within the colloidal sphere.

From Table 3 and in agreement with the corresponding energy spectrum for each radioisotope, it clearly appears that the Auger's and Internal Conversion's contributions to the emitted energy are radically different. Thus, we can observe that the Auger electrons may be neglected for ${ }^{132} \mathrm{I},{ }^{133} \mathrm{I}$ and ${ }^{134} \mathrm{I}$ whereas their contribution becomes more important for ${ }^{131} \mathrm{I}$ and particularly for ${ }^{135} \mathrm{I}$. Considering the Conversion electrons, their contributions are more important: of the order of $1 \%$ for ${ }^{133} \mathrm{I}$, of $1.5 \%$ for ${ }^{132} \mathrm{I}$ and ${ }^{134} \mathrm{I}$, of almost $5 \%$ for ${ }^{131} \mathrm{I}$ whereas they are negligible for ${ }^{135} \mathrm{I}$.

Table 2 - Theoretical Svalues (in Gy/Bq.s) deduced from our Monte Carlo simulation for the five radioiodine isotopes studied.

\begin{tabular}{cccccc}
\hline Isotopes & ${ }^{\mathbf{1 3 1}} \mathbf{I}$ & ${ }^{\mathbf{1 3 2}} \mathbf{I}$ & ${ }^{\mathbf{1 3 3}} \mathbf{I}$ & ${ }^{\mathbf{1 3 4}} \mathbf{I}$ & ${ }^{\mathbf{1 3 5}} \mathbf{I}$ \\
\hline $\begin{array}{c}\text { Mean energy emitted } \\
\text { per disintegration (keV) }\end{array}$ & 155 & 460 & 390 & 555 & 342 \\
S-values (Gy/Bq.s) & $1,022.10^{-4}$ & $6,503.10^{-5}$ & $6,581.10^{-5}$ & $5,965.10^{-5}$ & $7,596.10^{-5}$ \\
\hline
\end{tabular}

Table 3 - Emitted energy (for $1 \mathrm{~Gy}$ ) by the five radio iodine isotopes under consideration from the colloid: contributions of the $\beta$ spectrum, of the Auger electrons as well as the Conversion electrons.

\begin{tabular}{cccc}
\hline \multirow{2}{*}{ Isotopes } & \multicolumn{3}{c}{ Energy emitted from the colloid (for 1Gy) } \\
\cline { 2 - 4 } & $\boldsymbol{\beta}$ contribution & Auger contribution & Conversion contribution \\
${ }^{131} \mathrm{I}$ & $94.98 \%$ & $0.22 \%$ & $4.80 \%$ \\
${ }^{132} \mathrm{I}$ & $98.32 \%$ & $\cong 0 \%$ & $1.65 \%$ \\
${ }^{133} \mathrm{I}$ & $99.04 \%$ & $0.02 \%$ & $0.94 \%$ \\
${ }^{134} \mathrm{I}$ & $98.39 \%$ & $0.03 \%$ & $1.58 \%$ \\
${ }^{135} \mathrm{I}$ & $99.37 \%$ & $0.62 \%$ & $0.01 \%$ \\
\hline
\end{tabular}

In table 4 and 5 we have respectively reported the energy retained within the colloid and within the thyroid cells. The general observations made can be summarized as follows:

For the energy fraction remained within the colloid

The fraction of energy retained, denoted $P_{\text {colloide }}$, varies linearly with the mean $\beta$ energy $\overline{E_{\beta}}$ (reported in Table 1), what is coherent with the fact that the energy deposited within the colloid is all the more important that the $\beta$ energy is low. Thus, $P_{\text {colloide }}$ varies from $0.428 \%$ for ${ }^{134} \mathrm{I}$ (with $\overline{E_{\beta}}=580.9 \mathrm{keV}$ ) to $2.5 \%$ for ${ }^{131} \mathrm{I}$ (with $\left.\overline{E_{\beta}}=182.5 \mathrm{keV}\right)$.

The contribution of the Auger electrons, denoted $\Pi_{\text {colloide }}^{\text {Auger }}$, only depends on their relative abundance in the initial energy spectrum of the radio-iodine considered. This quantity has been denoted $f$ in Table 1. Thus, we observe that:

$$
\Pi_{\text {colloide }}^{\text {Auger }}\left({ }^{131} \mathrm{I}\right)>\quad \Pi_{\text {colloide }}^{\text {Auger }} \quad\left({ }^{134} \mathrm{I}\right)>\quad \Pi_{\text {colloide }}^{\text {Auger }}
$$
$\left({ }^{132} \mathrm{I}\right)>\Pi_{\text {colloide }}^{\text {Auger }}\left({ }^{133} \mathrm{I}\right)>\Pi_{\text {colloide }}^{\text {Auger }}\left({ }^{135} \mathrm{I}\right)$, what is coherent with $f\left({ }^{131} \mathrm{I}\right)>f\left({ }^{134} \mathrm{I}\right)>f\left({ }^{132} \mathrm{I}\right)>f\left({ }^{133} \mathrm{I}\right)>f\left({ }^{135} \mathrm{I}\right)$. Let us note that $\Pi_{\text {colloide }}^{\text {Auger }}$ is independent on the mean energy of the Auger electrons what is simply due to the fact that almost all the Auger electrons may be stopped within the colloid.

Similar observations can be made for $\Pi_{\text {colloide }}^{\text {Conversion }}$.

\section{For the energy fraction remained within the thyroid cells}

Concerning the fraction of energy deposited within the thyroid cells, denoted $P_{\text {cell, }}$, we observe similar tendencies as previously, namely a linear variation of the fraction $P_{\text {cell }}$ with the mean $\beta$ energy $\overline{E_{\beta}}$ : 
$P_{\text {cell }}$ is thus all the more important that the $\beta$ energy is low.

Table 4 - Energy amount retained within the colloid for a dose of 1Gy emitted from the colloid by the five radio iodine isotopes under consideration: contributions of the $\beta$ spectrum, of the Auger electrons as well as the Conversion electrons.

\begin{tabular}{|c|c|c|c|}
\hline Isotopes & \multicolumn{3}{|c|}{$\mathbf{P}_{\text {colloide }}$} \\
\hline \multirow[t]{2}{*}{${ }^{131} \mathbf{I}$} & $\Pi_{\text {colloide }}^{\beta}$ & $\begin{array}{c}\Pi_{\text {colloide }}^{\text {Auge }} \\
V(=2.5 \%)\end{array}$ & $\Pi_{\text {colloide }}^{\text {Conversion }}$ \\
\hline & $85.23 \%$ & $7.30 \%$ & $7.47 \%$ \\
\hline \multirow[t]{2}{*}{${ }^{132} \mathbf{I}$} & & $(=0.59 \%)$ & \\
\hline & $96.90 \%$ & $2.11 \%$ & $0.9 \%$ \\
\hline \multirow[t]{2}{*}{${ }^{133} \mathbf{I}$} & & $(=0.715 \%)$ & \\
\hline & $98.33 \%$ & $1.20 \%$ & $0.47 \%$ \\
\hline \multirow[t]{2}{*}{${ }^{134} \mathbf{I}$} & & $(=0.428 \%$ & \\
\hline & $90.99 \%$ & $4.90 \%$ & $4.11 \%$ \\
\hline \multirow[t]{2}{*}{${ }^{135} \mathbf{I}$} & & $(=0.922 \%$ & \\
\hline & $98.85 \%$ & $0.75 \%$ & $0.40 \%$ \\
\hline
\end{tabular}

Table 5- Energy amount retained within the thyroid cells for a dose of $1 \mathrm{~Gy}$ emitted from the colloid by the five radio iodine isotopes under consideration: contributions of the $\beta$ spectrum, of the Auger electrons as well as the Conversion electrons.

\begin{tabular}{|c|c|c|c|}
\hline \multirow{3}{*}{$\begin{array}{l}\text { Isotopes } \\
{ }^{131} \text { I }\end{array}$} & \multicolumn{3}{|c|}{$\mathbf{P}_{\text {cell }}$} \\
\hline & $\Pi_{\text {cell }}^{\beta}$ & $\Pi_{\text {cell }}^{\text {Auger }}$ & $\Pi_{\text {cell }}^{\text {Conversion }}$ \\
\hline & \multicolumn{3}{|c|}{$1,05.10^{6} \mathrm{eV}(2.33 \%)$} \\
\hline & $88.45 \%$ & $1.47 \%$ & $10.08 \%$ \\
\hline \multirow[t]{2}{*}{${ }^{132} \mathbf{I}$} & \multicolumn{3}{|c|}{$2,69.10^{5} \mathrm{eV}(=0.59 \%)$} \\
\hline & $98.30 \%$ & $0.61 \%$ & $1.07 \%$ \\
\hline \multirow[t]{2}{*}{${ }^{133} \mathbf{I}$} & \multicolumn{3}{|c|}{$3,2.10^{5} \mathrm{eV}(=0.726 \%)$} \\
\hline & $99.13 \%$ & $0.38 \%$ & $0.49 \%$ \\
\hline \multirow[t]{2}{*}{${ }^{134} \mathbf{I}$} & \multicolumn{3}{|c|}{$1,92.10^{5} \mathrm{eV}(=0.427 \%)$} \\
\hline & $94.56 \%$ & $0.89 \%$ & $4.55 \%$ \\
\hline \multirow[t]{2}{*}{${ }^{135} \mathbf{I}$} & \multicolumn{3}{|c|}{$4,1.10^{5} \mathrm{eV}(=0.913 \%)$} \\
\hline & $99.39 \%$ & $0.17 \%$ & $0.44 \%$ \\
\hline
\end{tabular}




\section{CONCLUSION}

In the present work we have described a numerical approach allowing a detailed microdosimetry of the complete disintegrations of the short-lived iodine isotopes as well as of ${ }^{131} \mathrm{I}$ in the thyroid gland. This latter is based on a new model coupling Secondary Ion Mass Spectrometry to Monte Carlo electron track-structure code.

The thyroid follicle has been modelled by two concentric spheres: a first one of $12 \mu \mathrm{m}$ diameter to represent the colloid itself and a second one of $20 \mu \mathrm{m}$ diameter to represent the cellular shell. Considering the disintegration modelling, all the charged particles emitted during irradiation have been followed until a low-energy cut-off $(12.6 \mathrm{eV})$ what allows, for the first time, to provide a dosimetry at the finest (cellular) scale. Quantitative data have then been reported concerning the role played by the short-lived iodine isotopes in the final energetic cartography in the follicle as well as the thyroid cells.

\section{ACKNOWLEDGEMENTS}

This study was supported by grant RB 2005- 09 from Electricité de France.

\section{RESUMO}

O impacto mais significante do acidente de Chernobyl é o crescimento da incidência de câncer de tireóide em crianças que foram expostas a radioiodos de vida curta e ao Iodo-131. Na estimativa precisa da dose de radiação fornecida por esses radioiodos, é necessário conhecer onde o iodo está incorporado. Para obtermos esse resultado, a distribuição em nível celular de iodo recentemente organificado na tireóde de ratos imaturos foi realizada usando microscopia de massa iônica secundária $\left(\right.$ NanoSIMS $\left.{ }^{50}\right)$. Modelos dosimétricos atuais consideram apenas a energia média das partículas beta dos radioelementos e pode, imperfeitamente descrever a distribuição real de dose ao nível microscópico em torno dos pontos pesquisados. Nossa abordagem é radicalmente diferente desde que é baseada na simulação de Monte Carlo permitindo acompanhar os elétrons de energias menoress $(\approx 10 \mathrm{eV})$ o que permite uma descrição nanométrica da física da radiação. As simulações numéricas foram então realizadas pelo modelo de desintegração completa de isotopos do iodo de vida curta assim como do Iodo-131 em tireóide de ratos recém nascidos na tentativa de obter resultados biológicos e histológicos de maior precisão para a glândula tireóide.

\section{REFERENCES}

Balonov, M., Kaidanovsky, G., Zvonova, I., Kovtun, A., Bouville, A., Luckyanov, N., Voillequé, P. (2003), Contributions of short-lived radioiodine to thyroid doses received by evacuees from the Chernobyl area estimated using early in vivo activity measurements. Radiat. Prot. Dosimetry, 105, 593599.

Bleuer, J. -P., Averkin, Y. I., Abelin, T. (1997), Chernobyl-related thyroid cancer: what evidence for short-lived iodines? Health Perspect., 105, 14831486.

Cardis, E., Kerminiene, A., Ivanov, V., Malakhova, I., Shibata, Y., Khrouch, V. (2005), Risk of thyroid cancer after exposure to ${ }^{131} \mathrm{I}$ in childhood. J. Natl. Cancer Inst., 97, 724-732.

Champion, C., Hanssen, J., Hervieux, P. -A. (2002), Electron impact ionization of water molecule. $J$. Chem. Phys., 117, 197-204.

Champion, C. (2003), Theoretical cross sections for electron collisions in water: structure of electron tracks. Phys. Med. Biol., 48, 2147-2168.

Champion, C. (2005), Moving from Organ Dose to Microdosimetry: Contribution of the Monte Carlo Simulations. Braz Arch Biol Technol, 48, 191-199.

Champion, C., Hanssen, J., Hervieux, P. -A. (2004), Differential and total (e, 2e) cross sections of simple polyatomic molecules. J. Chem. Phys., 121, 94239429.

Champion, C., Dal Cappello, C., Houamer, S., Mansouri, A. (2006), Single ionization of the watermolecule by electron impact: Angular distributions at low incident energy. Phys. Rev. A., 73, 012717.

Champion, C., Le Loirec, C. (2006), Positron follow-up in liquid water: I. A new Monte Carlo track-structure code. Phys. Med. Biol., 51, 1707-1723.

Goulko, G. M., Chumak, V. V., Chepurny, N. I., Henrichs, K., Jacob, P., Kairo, I. A., Likhtarev, I. A., Repin, V. S., Sobolev, B. G., Voigt, G. (1996), Estimation of thyroid doses from the evacuees from Pripyat. Radiat. Environ. Biophys., 35, 81-87.

Guerquin-Kern, J. L., Hillion, J. C., Madelmont, J. C., Labarre, P., Papon, J., Croisy, A. (2004), Ultrastructural cell distribution of the melanoma marker iodobenzamide: improved potentiality of SIMS imaging in life sciences. Biomed. Eng. Online, 3, 10. 
Guerquin-Kern, J. L., Wu, T. D., Quintana, C., Croisy, A. (2005), Progress in analytical imaging of the cell by dynamic secondary ion mass spectrometry. Biochim. Biophys. Acta, 1724, 228-38.

Heidenreich, W. F., Kayro, I., Chepurny, M., Jacob, P., Spak, V., Goulko, G. M., Paretzke, H. G. (2001), Age- and sex-specificity relative thyroid radiation exposure to ${ }^{131} \mathrm{I}$ in Ukraine after the Chernobyl accident. Health Phys, 80, 242-50.

Jacob, P., Kenigsberg, Y., Zvonova, I., Goulko, G., Buglova, E., Heidenreich, W. F., Golovneva, A., Bratilova, A.. A., Drozdovitch, V., Kruk, J., Pochtennaja, G. T., Balonov, M., Demidchik, E. P., Paretzke, H. G. (1999), Childhood exposure due to the Chernobyl accident and thyroid cancer risk in contaminated areas of Belarus and Russia. Brit. J. Cancer, 80, 1461-1469.

Loevinger, R., Berman, M. A. (1968), A formalism for calculation of absorbed dose from radionuclides. Phys. Med. Biol., 13, 205-217.

Milne-Brownlie, D. S., Cavanagh, S. J., Lohmann, B., Champion, C., Hervieux, P. -A., Hanssen, J. (2004), Dynamics in electron impact ionization of $\mathrm{H}_{2} \mathrm{O}$. Phys. Rev. A., 69, 032701.
Moccia, R. (1964), One-center basis set SCF MO's. III. $\mathrm{H}_{2} \mathrm{O}, \mathrm{H}_{2} \mathrm{~S}$, and HCl. J. Chem. Phys., 40, 2186-2192.

Sinclair, W. K., Abbatt, J. D., Farran, H. E., Harriss, E. B., Lamerton, L. F. (1956), A quantitative autoradiographic study of radioiodine distribution and dosage in human thyroid gland. Brit. J. Radiol., 337, 36-41.

Shibata, Y., Yamashita, S., Masyakin, W. B., Panasyuk, G. D., Nagataki, S. (2001), 15 years after Tchernobyl: new evidence of thyroid cancer. Lancet, 358, 19651966.

Uehara, S. (1986), The development of a Monte Carlo code simulating electron-photon showers and its evaluation by various transport benchmarks. Nucl. Inst. Methods B., 14, 559.

Uehara, S., Nikjoo, H., Goodhead, D. T. (1992), Crosssections for water vapour for the Monte Carlo electron track structure code from $10 \mathrm{eV}$ to the $\mathrm{MeV}$ region. Phys. Med. Biol., 37, 1841-1858.

Zanzonico, P. B. (2000), Age-dependent thyroid absorbed doses for radiobiologically significant radioisotopes of iodine. Health Phys., 78, 60-67. 